\title{
Tannin extracts from immature fruits of Terminalia chebula Fructus Retz. promote cutaneous wound healing in rats
}

\author{
Kun Li', Yunpeng Diao², Houli Zhang ${ }^{2}$, Shouyu Wang ${ }^{2}$, Zhen Zhang ${ }^{2}$, Bo Yu' , Shanshan Huang ${ }^{2}$ and Hong Yang ${ }^{1 *}$
}

\begin{abstract}
Background: Tannins extracted from immature fruits of Terminalia chebula Fructus Retz. are considered as effective components promoting the process of wound healing. The objective of this study is to explore the optimal extraction and purification technology (OEPT) of tannins, while studying the use of this drug in the treatment of a cutaneous wound of rat as well as its antibacterial effects.

Methods: The content of tannin extracts was measured by the casein method, and antibacterial ability was studied by the micro-dilution method in vitro. In wound healing experiment, animals in group I, II and III were treated with vaseline ointment, tannin extracts (tannin content: $81 \%$ ) and erythromycin ointment, respectively (5 mg of ointment were applied on each wound). To evaluate the process of wound healing, selected pharmacological and biochemical parameters were applied.
\end{abstract}

Results: After optimal extraction and purification, content of tannin extracts was increased to $81 \%$. Tannin extracts showed the inhibition of Staphylococcus aureus and Klebsiella Pneumonia in vitro. After excision of wounds, on days 7 and 10, the percent of wound contraction of group II was higher than that of group I. After being hurt with wounds, on days 3, 7, and 10, the wound healing quality of group II was found to be better than that of group I in terms of granulation formation and collagen organization. After wound creation, on day 3, the vascular endothelial growth factor expression of group II was higher than that of group I.

Conclusion: The results suggest that tannin extracts from dried immature fruits of Terminalia chebula Fructus Retz. can promote cutaneous wound healing in rats, probably resulting from a powerful anti-bacterial and angiogenic activity of the extracts.

\section{Background}

Wound healing may be a challenging medical issue that requires specialized treatment and care. Although tannin extracts have been used in improving the process of wound healing [1], the chemical components of the extracts and their mechanisms in vivo have not been completely understood till date. In recent years, for human and veterinarian use, many research studies have indicated an interest in exploring drugs obtained from plants with a high content of tannins. These are potentially useful in promoting the healing of wounds and burns. Tannins could promote cicatrisation of wounds

\footnotetext{
* Correspondence: doctordiaodiao@163.com

${ }^{1}$ College of Life Sciences, Liaoning Normal University, Dalian 116029, PR China

Full list of author information is available at the end of the article
}

through several cellular mechanisms: i) chelation of free radicals and reactive species of oxygen, ii) promoting contraction of the wound, and iii) increasing formation of capillary vessels and fibroblasts [2]. The immature fruit of Terminalia chebula Fructus Retz is found in Yunnan, Tibet, Guangdong, and Guangxi provinces of China and has been termed as Xiqingguo in Chinese. It is also found in Malaysia, Thailand, India, and Pakistan [3-6]. Its use for medicinal purposes has been historically accredited in Ayurvedic literature. In Thai folk, it is considered as a natural remedy for skin diseases, wound healing, and rejuvenation [7].

Many local factors can affect the development of wounds. Bacterial infection is the most important factor that can impact the development of wounds $[8,9]$. Recent researches suggest that bacteria release

\section{() Biomed Central}


proteolytic enzymes to digest the connective tissue of skin, resulting in tissue necrosis and wound expansion. Tissue necrosis and liquefaction can promote bacterial growth. The above factors can interact with each other, aggravating the pathological condition and eventually resulting in extensive infection and sepsis. Infection usually involves bacteria with strong pathogenicity, such as Staphylococcus aureus and Pseudomonas aeruginosa, etc. On the other hand, Escherichia coli and Klebsiella pneumoniae are prone to produce extended-spectrum $\beta$ lactamases (ESBLs) [10]. It has been found that some plant phenolics, including flavonoids and tannins have antibacterial effects [11-13].

Cutaneous wound healing is a complex process, which consists of progression of inflammation, angiogenesis, collagen deposition, reepithlization, and tissue remolding [14]. The purpose of repairing events is to resist pathogens invasion, establish integrity of damaged tissue, and reconstruct physiological function of the skin [15].

Vascularization is a process that involves vascular endothelial cells differentiation and proliferation to form a new vascular system. The process lays an important foundation for wound healing. In human tissues, new vessels would stop growing after fulfilling the normal physiological needs. With a molecular weight of 34-45 $\mathrm{KD}$, endothelial cell growth factor (VEGF) was considered as one of the important regulatory factors. VEGF can activate biological activities by forming dimmers with glycoprotein monomers undergoing disulfide bonds. VEGF is considered the strongest mitogen for the proliferation of vascular endothelial cells [16]. In recent times, several other factors, including the placenta growth factor (PIGF), VEGF-A, -B, -C, -D and -E were found to have similar functions. All of the factors were defined in terms of VEGF family [17]. The amino acid sequence is also considered as highly conserved. The factors bind homotyrosine kinase receptor, playing key roles in physiological and pathological processes of embryonic development and wound healing.

In our present work, we study an optimal extraction and purification of tannin extracts from the immature fruit of Terminalia chebula Fructus Retz. To study the efficiency of tannin extracts on wound healing, angiogenesis, and VEGFA expression, we used rat model of wound excision. We also analyzed antibacterial effects of tannin extracts.

\section{Methods}

\section{Plant material}

In July, 2010, immature fruits of Terminalia chebula Fructus Retz. were purchased from the Dalian Nepstar Chain Drug Store of Liaoning province in China. The fruits were identified by Dr. Yun-Peng Diao, a professor of Dalian Medical University. The voucher specimen was deposited in a pharmacognosy laboratory along with a given specimen number XT001.

\section{Optimization of extraction and purification technology and preparation of extracts}

Tannin extracts were temperature-sensitive. According to requirements of production, temperature during extraction was set to $50^{\circ} \mathrm{C}$, and water was considered as the extraction solvent. Four factors can affect extraction: (A) duration of extraction, (B) maceration time, (C) extract-solvent ratio, and (D) number of extraction. The study was conducted in accordance with the orthogonal test of four factors at three different levels. The immature fruit powder of Terminalia chebula Fructus Retz. (10 g in weight) was extracted with water $(100 \mathrm{ml})$ at $50^{\circ} \mathrm{C}$. Thereafter, the extracts were weighted. Content of tannin extracts was measured and optimal extraction and purification technology (OEPT) was determined. The extracts were added to ethanol of $95 \%$ concentration, and the concentration of extract solutions were diluted to $80 \%$. The extract solution was deposited for 12 hours and centrifuged at $4000 \mathrm{rpm}$ for $10 \mathrm{~min}$. After filtration, the content of tannin extracts was analyzed by the casein method.

Table 1 enlists the data of orthogonal test.

\section{Determination of content of tannin extracts}

The content of tannin extracts was measured by the casein method described in China Pharmacopoeia [18].

\section{Preparation of reference solution}

In a $25 \mathrm{ml}$ brown measuring flask, reference substance solutions (0.05 g gallic acid per $\mathrm{ml}$ ) in aliquots of 1.0 $\mathrm{ml}, 2.0 \mathrm{ml}, 3.0 \mathrm{ml}, 4.0 \mathrm{ml}$, and $5.0 \mathrm{ml}$ were separately placed. Then, $1 \mathrm{ml}$ phosphotungstomolybdic acid was added to each of these aliquots. Thereafter, $11 \mathrm{ml}, 10$ $\mathrm{ml}, 9 \mathrm{ml}, 8 \mathrm{ml}$, and $7 \mathrm{ml}$ of water were respectively added to each of these aliquots. Finally, they were diluted to a volume of $25 \mathrm{ml}$ using $29 \% \mathrm{Na}_{2} \mathrm{CO}_{3}$ solution. Absorbance of the reaction mixture was read at $760 \mathrm{~nm}$. A calibration curve of gallic acid (ranging from 1 to $10 \mu \mathrm{g} / \mathrm{ml}$ ) was prepared.

\section{Procedure of determination}

Total phenol content was determined as follows: $2 \mathrm{ml}$ sample solution was poured into a $25 \mathrm{ml}$ brown measuring flask. Then, $10 \mathrm{ml}$ water was added to it and absorbance was measured. The content of the mixture was determined using a standard curve. Non-adsorbed polyphenol content was determined as follows: $25 \mathrm{ml}$ sample solution was poured into a $100 \mathrm{ml}$ stoppered conical flask, containing previously added $0.6 \mathrm{~g}$ casein. The mixture was stored in a water bath at $30^{\circ} \mathrm{C}$ for 1 hour; $2 \mathrm{ml}$ filtrate was accurately measured in a $25 \mathrm{ml}$ brown 
Table 1 The orthogonal test of four factors at three different levels

\begin{tabular}{ccccc}
\hline Factors & A duration of extraction (hour) & B maceration time $(\mathbf{m i n})$ & C extract-solvent ratio(times) & D number of extraction(times) \\
\hline 1 & 1 & 20 & 10 & 1 \\
2 & 1.5 & 40 & 15 & 2 \\
3 & 2 & 60 & 20 & 3 \\
\hline
\end{tabular}

measuring flask and $10 \mathrm{ml}$ of water was added. After measuring the absorbance, the content of the mixture was determined using a standard curve. Tannin content of the solution was calculated with the following formula: Content of the tannin extracts $=($ Total phenol content)-(Non-adsorbed polyphenol content).

\section{Antibacterial activity}

Antibacterial activity of the tannin extracts was studied after taking into account staphylococcus aureus (ATCC25923) and Klebsiella pneumonia (ATCC700603). Antibacterial ability was studied by the micro-dilution method. Using reference antimicrobial drugs like penicillin and cefoperazone sodium (NCCLS, 2000), minimum inhibitory concentration (MIC) and minimum bactericidal concentration $(\mathrm{MBC})$ were determined. After activation and culture development for 24 hours, 2\% of Staphylococcus aureus and Klebsiella Pneumonia were separately inoculated in broth-based media containing minimum inhibitory concentration of tannins extracts at $37^{\circ} \mathrm{C}$ with shaking at $120 \mathrm{rpm}$. After adding tannin extracts and centrifugation, a total of $3 \mathrm{ml}$ medium was collected at intervals of $4 \mathrm{~h}, 24 \mathrm{~h}$, and $30 \mathrm{~h}$. The collected bacteria sediment was washed with phosphate buffer three times. The obtained bacteria were used for preparing specimen. Morphologic and structure changes of the bacteria were observed, using a KYKY-1000B scanning electron microscope.

\section{Animal preparation and treatment}

Adult male Sprague-Dawley rats, weighing 200-220 g, were supplied by the Animal Experimental Center of Dalian Medical University. Before conducting the study, each rat was housed in an individual cage in the same room for 1 week. The controlled environment included the following parameters: 12-hour light/dark cycle, $23 \pm$ $2{ }^{\circ} \mathrm{C}$, and relative humidity $70 \%$. The rat was given free access to a standard laboratory diet and water. All experimental procedures were approved by the Animal Research Ethics Committee of Dalian Medical University, Dalian, China (DMU10/02/23).

The rat was anesthetized with intra-peritoneal injection of $10 \%$ chloral hydrate $(0.3 \mathrm{ml} / 100 \mathrm{~g})$. The dorsal surface of the rat was shaved, and the underlying skin was cleaned with povidone iodine. An acute excision circle of $1.5 \mathrm{~cm}$ in diameter was engraved on the wound, using a scalpel blade on the back of the rat. The rats were then randomly divided into group I, II, and III (36 rats in each group). The wound of group I was treated with vaseline ointment at a dosage of $5 \mathrm{mg}$ per wound, serving as a negative control. The wound of group II was treated with tannin extracts at a dosage of $5 \mathrm{mg}$ per wound. The wound of group III was treated with erythromycin ointment (Approval Number: H11021246, Beijing Shuangji Pharmacy Co,. Ltd, China) at a dosage of $5 \mathrm{mg}$ per wound, serving as a positive control. All drugs were applied topically every other day, until a complete healing of wounds was achieved.

\section{Wound measurement}

After wound creation, six rats of each group were randomly selected and sacrificed on days 1, 3, 7, 10, 14, and 21 , respectively. The wound diameter was measured, and the area $\left(\mathrm{cm}^{2}\right)$ within the boundary was calculated planimetrically. The percentage of wound contraction was determined using the following formula: percentage of wound contraction $=[$ (original wound area - unhealed area)/original wound area] $\times 100 \%$.

\section{Histological examination of excised tissue}

The excised wound tissue was fixed in $10 \%$ neutral buffered formalin. It was dehydrated in graded ethanol, cleared in xylene, and embedded in paraffin. On the glass slides, five-micron-thick sections of the epidermis, dermis, and subcutaneous panniculus carnosus muscle have been mounted. After dewaxing the sample, it was rehydrated to distilled water and stained with hematoxylin and eosin. All subsequent analyses were performed by an experienced pathologist without knowledge of the previous treatments. Based on the degree of re-epithelization, granulation tissue formation, and collagen organization, a five-tiered grading system was adopted to evaluate the historical differences of different samples, as showed in Table $2[19,20]$.

\section{Immunohistochemical analysis of VEGFA expression}

The selected wound tissue sections were deparaffinized and redehydrated after holding at $60{ }^{\circ} \mathrm{C}$ for $2 \mathrm{~h}$. Thereafter, $3 \% \mathrm{H}_{2} \mathrm{O}_{2}$ in methanol was used for 10 min to prevent endogenous peroxidase activity. The section was boiled in $0.01 \mathrm{~mol} / \mathrm{L}$ citric acid for $20 \mathrm{~min}$ for retrieving antigen. To prevent nonspecific binding, normal goat serum was applied at $37^{\circ} \mathrm{C}$ for $10 \mathrm{~min}$. The section was then reacted mouse anti-rat VEGFA monoclonal antibody (diluted 1:5, Abcam, UK) at $37^{\circ} \mathrm{C}$ for $1 \mathrm{~h}$. After 
Table 2 Score of historical evaluation

\begin{tabular}{cccc}
\hline Score & Re-epithelialization & Granulation tissue formation & Collagen organization \\
\hline 0 & None & None & None \\
1 & Migrating & Hypo cellular with few vessels & Trace \\
2 & Partial stratum corneum & Many vessels and some cells & Slight \\
3 & Hypertrohic & Many fibroblasts, some fibers & Moderate \\
4 & Complete and normal & More fibers, few cells & Marked \\
\hline
\end{tabular}

washing with phosphate buffered saline, the section was first incubated with bio-tinylated goat anti-mouse antibody (Beijing Zhongshan Biology Technology Co., Ltd, China) at $37^{\circ} \mathrm{C}$ for $30 \mathrm{~min}$. Then, the same process was repeated using horseradish peroxidase-labeled streptavidin at $37^{\circ} \mathrm{C}$ for $30 \mathrm{~min}$. After staining with 3, 3'-diaminobenzidine $(\mathrm{DAB}) / \mathrm{H}_{2} \mathrm{O}_{2}$ and hematoxylin, the section was dehydrated, cleared, and mounted for viewing. For VEGFA analysis, the section was first examined under a microscope $(100 \times$ magnification $)$ to identify the highest positive expression in the wound. Then, five areas of the highest expression were selected for evaluating under a microscope $(400 \times$ magnification). To calculate the area, density mean, and integrated optical density of positive expression, image was analyzed using Image-pro-plus 6.0 software (Media Cybernetics, USA). The average result of the five areas was recorded in terms of the statistic data of this wound tissue.

\section{Analysis of VEGFA mRNA expression by RT-PCR}

cDNA was synthesized using RT-PCR kit (TaKaRa, Japan) according to the manufacturer's protocol. Total RNA was isolated from homogenized excised tissues using Trizol (BBI, USA). The oligonucleotide sequences of the primers of VEGFA were 5'-TGCACCCACGACAGAAGGGGA-3' for sense and 5'- TCACCGCCTTGGCTTGTCACAT-3' for antisense. On the other hand, used as a control, the sequences of primer of GAPDH were 5'GGCCGTGAAGTCGTCAGAAC-3' for sense and 5'GCCACGATGCCCAGGAA-3' for antisense. PCR conditions were expressed as follows: denaturation at $95^{\circ} \mathrm{C}$ for 3 minutes, and then 30 cycles of denaturation for 20 seconds at $94^{\circ} \mathrm{C}$, annealing for 30 seconds at $55^{\circ} \mathrm{C}$, and extension for 30 seconds at $72^{\circ} \mathrm{C}$. Five $\mu \mathrm{l}$ PCR products were separated by electrophoresis using 1.0\% agarose gel and photographed under ultraviolet radiation light. Band intensity was measured by using Gel-Pro Analyzer 6.0 software (Media Cybernetics, USA) and was normalized to those for GAPDH.

\section{Results}

\section{Preparation of extracts and determination of optimal} extraction and purification

According to an orthogonal test, optimal extraction and purification was determined at three different levels using four factors. Table 3 represents the results of the orthogonal test. The results showed that the order of influencing factors as following: $\mathrm{D}>\mathrm{B}>\mathrm{C}>\mathrm{A}$. Number of extraction was more important than other factors for extraction, and duration of extraction was least important. Therefore, an extraction lasting for duration of 1 hour could be considered as appropriate for the test. The OEPT was set $\left(A_{1} B_{1} C_{2} D_{3}\right)$ as following: the immature fruit powder $(10 \mathrm{~g})$ was macerated for $20 \mathrm{~min}$ and then extracted three times with water (extract-solvent ratio $=1: 15$ ) for a time duration of $1 \mathrm{~h}$ at $50^{\circ} \mathrm{C}$. Ethanol of $80 \%$ concentration was added to these extracts and placed for $12 \mathrm{~h}$. The extracted solution was centrifuged at $4000 \mathrm{rpm}$ for $10 \mathrm{~min}$ and filtered. The content of tannin extracts was analyzed by casein method.

\section{Determination of content of tannin extracts}

Regression equation was calculated in the form $\mathrm{Y}=\mathrm{aX}$ $+\mathrm{b}$. In the formula, $\mathrm{X}$ and $\mathrm{Y}$ are concentration of standard solution $(\mathrm{mg} / \mathrm{mL})$ and corresponding absorbance. a and b correspond to slope and intercept, respectively. A calibration curve of gallic acid (ranging from 1 to $10 \mu \mathrm{g} /$ $\mathrm{ml}$ ) was prepared and listed in Figure 1. According to

\section{Table 3 The result of orthogonal test}

\begin{tabular}{cccccccc}
\hline No & A & B & C & D & $\begin{array}{c}\text { extract weight } \\
\text { (\%)y1 }\end{array}$ & $\begin{array}{c}\text { TTC(\%) } \\
\text { y2 }\end{array}$ & $\begin{array}{c}\text { score } \\
\mathbf{z}\end{array}$ \\
\hline 1 & 1 & 1 & 1 & 1 & 56.76 & 22.54 & 73.79 \\
2 & 1 & 2 & 2 & 2 & 69.10 & 24.97 & 85.14 \\
3 & 1 & 3 & 3 & 3 & 73.18 & 30.92 & 98.65 \\
4 & 2 & 1 & 2 & 3 & 72.14 & 31.63 & 99.44 \\
5 & 2 & 2 & 3 & 1 & 34.94 & 26.04 & 68.46 \\
6 & 2 & 3 & 1 & 2 & 64.81 & 24.73 & 82.34 \\
7 & 3 & 1 & 3 & 2 & 62.08 & 30.09 & 91.09 \\
8 & 3 & 2 & 1 & 3 & 65.58 & 28.54 & 89.99 \\
9 & 3 & 3 & 2 & 1 & 52.24 & 24.25 & 74.56 \\
K1 & 257.58 & 264.32 & 246.12 & 216.81 & & & \\
K2 & 250.24 & 243.59 & 259.14 & 258.57 & & & \\
K3 & 255.64 & 255.55 & 258.20 & 288.08 & & & \\
k1 & 85.86 & 88.11 & 82.04 & 72.27 & & & \\
k2 & 83.41 & 81.20 & 86.38 & 86.19 & & & \\
k3 & 85.21 & 85.18 & 86.07 & 96.03 & & & \\
R & 2.45 & 6.91 & 4,34 & 23.76 & & & \\
\hline Z & & & & & & & \\
\hline
\end{tabular}




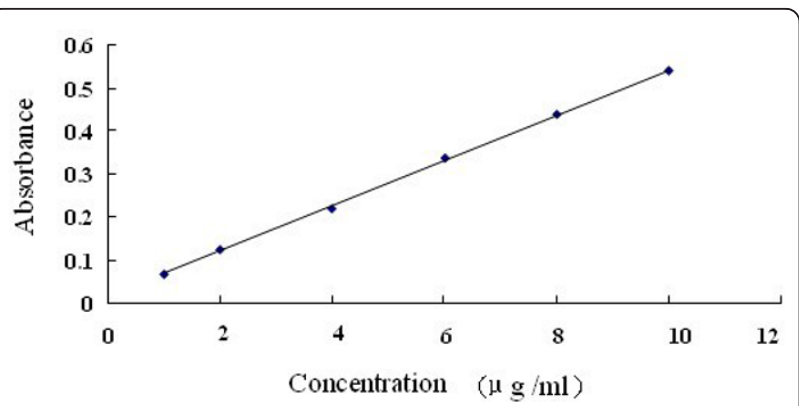

Figure 1 The calibration curve of gallic acid. linear range (1 10 $\mu \mathrm{g} / \mathrm{ml})$, Regression equation $(Y=a X+b): y=52.496 x+0.0163, R^{2}=$ $0.9993(n=6)$

the OEPT, the content of tannin extracts was estimated to be $81 \%$.

\section{Antibacterial activity}

The micro-dilution method was used to study the inhibitory and bactericidal effects of tannin extracts against the pathogens. Tannin extracts showed inhibitory activity against gram- negative bacteria Klebsiella pneumonia (MIC value $0.3125 \mathrm{mg} / \mathrm{ml}$ and MBC value $0.625 \mathrm{mg} / \mathrm{ml}$ ) and gram- positive bacteria Staphylococcus aureus (MIC value $0.3125 \mathrm{mg} / \mathrm{ml}$ and $\mathrm{MBC}$ value $1.25 \mathrm{mg} / \mathrm{ml}$ ).

After treating the tannin extract, we observed that the Staphylococcus aureus and Klebsiella pneumonia had morphologic changes under electron microscope. The changes were obviously compared with the bacteria of the control group. A normal bacterium shows smooth surface, plump appearance, and good refraction. At 24 hours after treatment, majority of the bacteria of group II became obviously shrank, dry, and distorted. Some bacteria became obviously depressed, vesicular, or irregular. The changes showed that tannin extracts of a MIC concentration could obviously destroy those two kinds of bacteria. Results have been shown in Figure 2.

\section{Wound contraction}

The areas of the original wounds of group I, II, and III were $1.81 \pm 0.22 \mathrm{~cm}^{2}, 1.80 \pm 0.11 \mathrm{~cm}^{2}$, and $1.80 \pm 0.19$ $\mathrm{cm}^{2}$, respectively. As far as percentage of wound contraction was concerned, no significant difference was found among the groups on days 1, 3, 14, and 21 after wound creation. On days 7 and 10, percentage of wound contraction of either group II or III was higher than that of group I with significant difference $(\mathrm{P}<$ 0.05). All wounds were healed prior to day 21 (Additional file 1, Table S1).

\section{Histological examination of excised tissues}

On the first day after treatment, re-epithelialization, granulation, and collagen deposition were similarly developed in three groups. The wound showed migrating reepithelialization, abundant fibrinous exudation, few vessels, and trace collagen. At the third day, the wound of group II illustrated an excessive proliferation of granulation tissue. The wound of group III showed proliferation of newly formed micro-vessels and accumulation of inflammatory cells and fibroblast (Figure 3). At the seventh and tenth days, the wounds of all three groups displayed a continuous epithelial line that covered the whole wound bed. Wound granulation of group II and III was matured. The wound showed capillary vertically orientation, robust fusiform fibrocytes, and moderate well-arranged collagen. The granulation tissue of the wound of group I was not matured. The tissue had poorly organized capillary, multiple fibroblast, and slight collagen formation. Except for reepithelialization value, the mean values of parameter related to wound healing of group II and III were higher than that of group I $(\mathrm{P}<0.05)$. On the fourteenth day, wound healing was observed in almost all the wounds. On the twentieth day, healing of wounds was observed in all wounds. In terms of histological changes, we found no significant difference among the three groups (Additional file 2, Table S2).

\section{Immunohistochemical examination of VEGFA expression}

On the first day, we found no significant difference among the three groups, in terms of the wound area, DM, and IOD of VEGFA expression. On the third day, the above parameters of group II and III were higher than those of group I, $(\mathrm{P}<0.05)$. On the third day, in all groups, we observed the VEGFA expression at the climax along the curve of the whole healing process (Figure 4). The VEGFA expression decreased on the seventh and tenth days. In addition, we found no significant difference in VEGFA expression at other time points (Additional file 3, Table S3).

\section{VEGFA mRNA expression determined by RT-PCR}

On the third day, VEGFA mRNA expression of the wound was observed among all three groups after determining it through the RT-PCR technique (Figure 5). The expression of both group II and group III was higher than that of group I $(P<0.05)$. At other time points, no significant difference was reported in the expression among the three groups.

\section{Discussion}

Botanical drugs such as sanguisorbae, rhubarb, acaciae catechu can be effective in the treatment of a thermal burn. Earlier experiments have attributed its effectiveness to tannin [21]. Tannins, polyphenolic compounds of various molecular weights, can be found abundantly in nature and have the ability to precipitate proteins [22]. With a molecular weight ranging from 500 and 


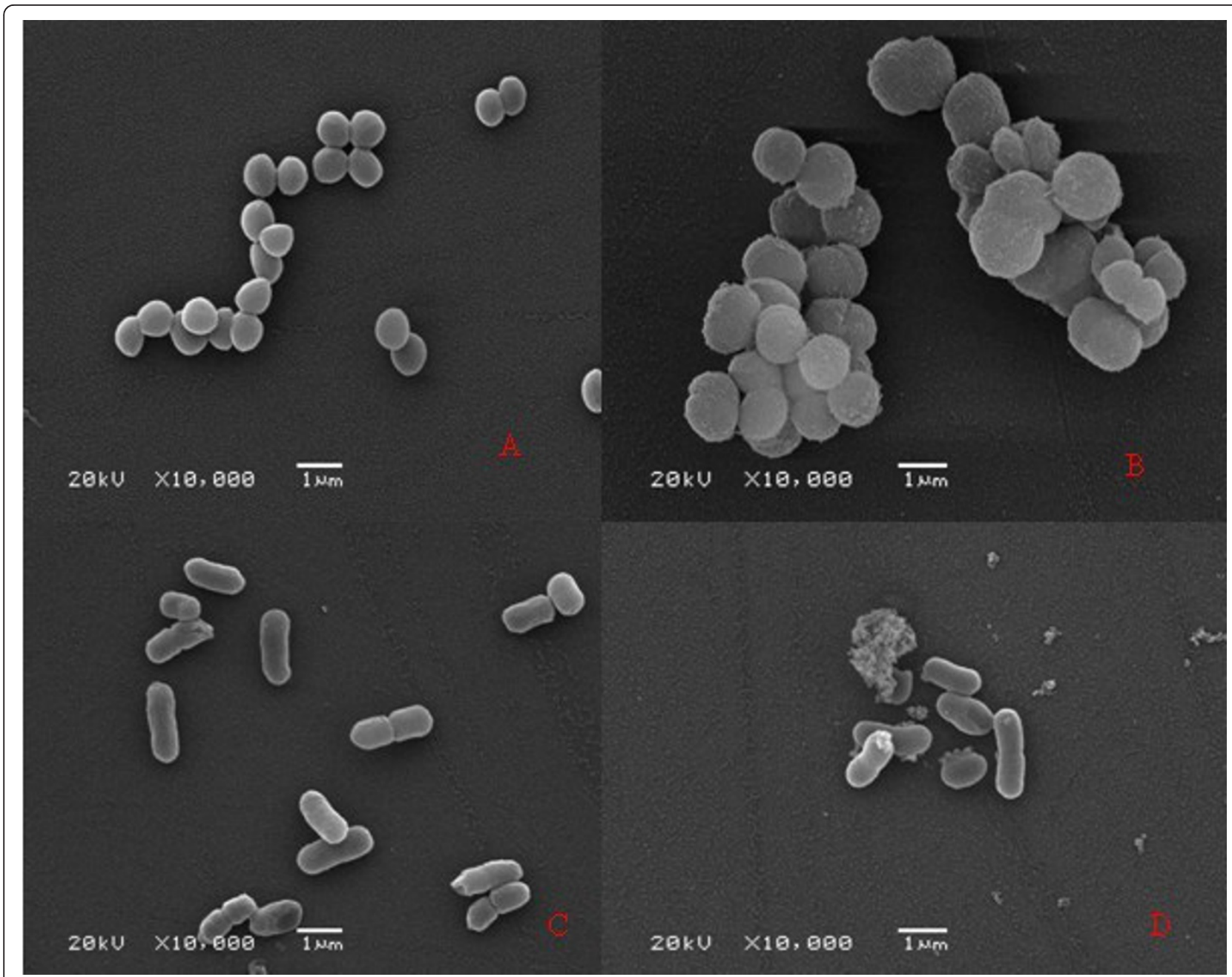

Figure 2 Morphology of Staphylococcus aureus and Klebsiella Pneumonia under scanning electron microscope. A the normal morphology of Staphylococcus aureus; B the morphology of Staphylococcus aureus on 24 h; C the normal morphology of Klebsiella Pneumonia; D the morphology of Klebsiella Pneumonia on $24 \mathrm{~h}$

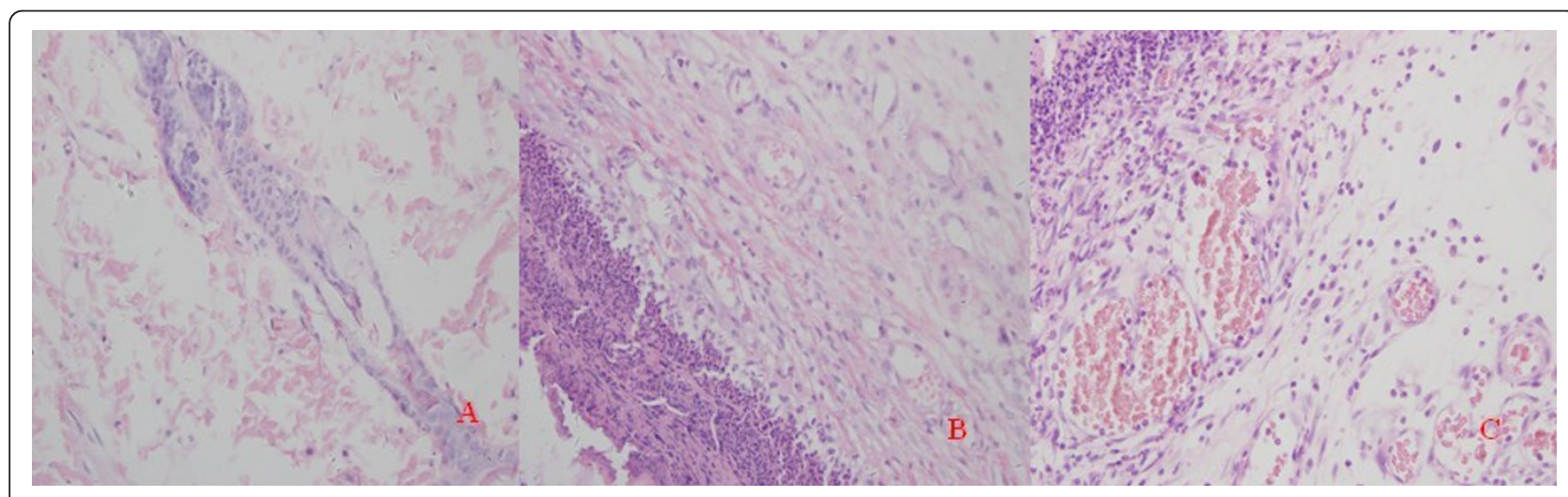

Figure 3 Histological compare in the character of wound healing on day 3. (100 × magnification). A: groupl; B: groupll; C: grouplll 


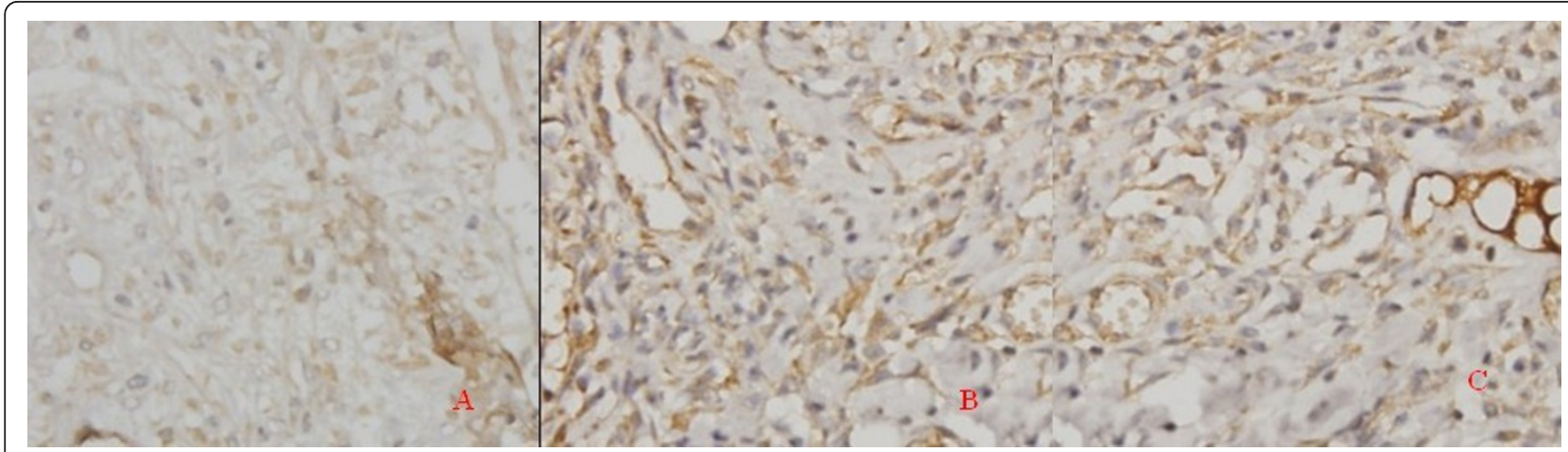

Figure 4 Immunohistochemical examination of VEGFA expression on day 3. (400 $\times$ magnification). A: groupl; B: groupll; C: group III

$4000 \mathrm{Da}$, these materials are soluble in water. They constitute a significant group of secondary ingredients of plants [23]. In the present study, based on evaluation of potentials of Terminalia chebula Fructus Retz., we showed that tannin extracts has antimicrobial effects and application of the drug would improve wound healing.

When we extracted and purified tannin, we used water and alcohol for dissolution given the requirement of industrialized production as well as safety. It further determined the optimum extraction and purification

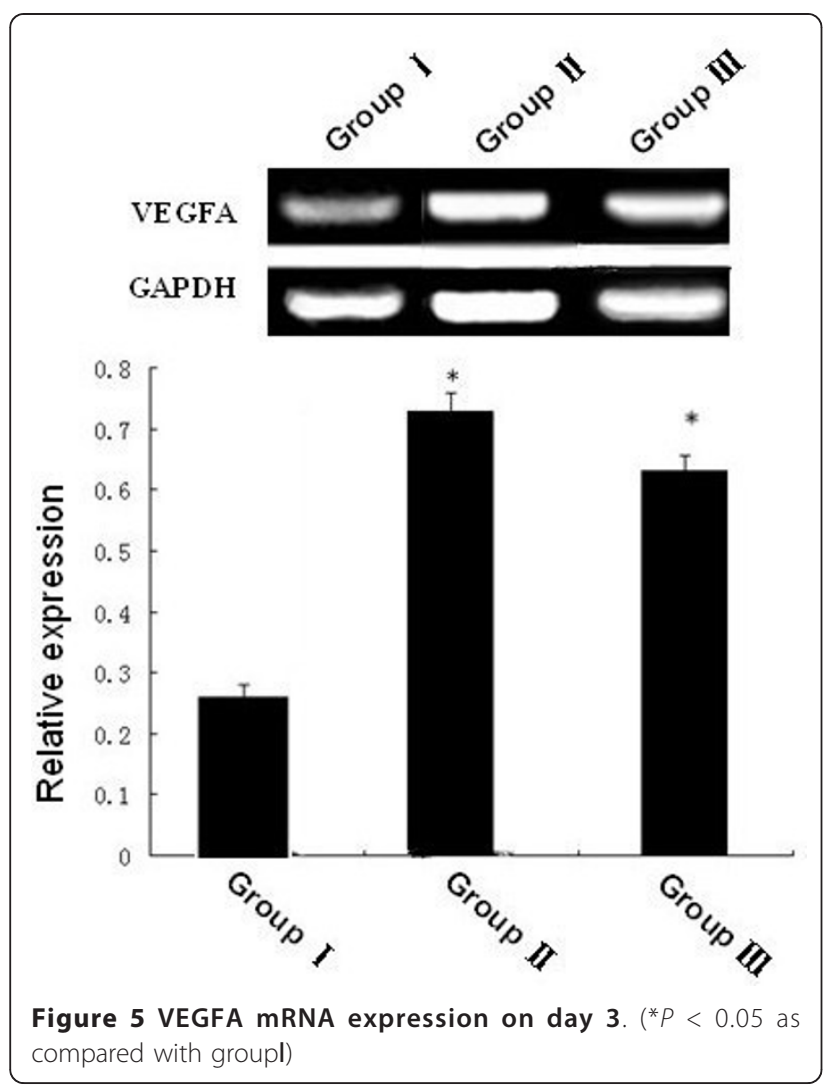

technology (OEPT) of tannin extracts in order to ensure the high tannin content.

It is well-known that a wound is prone to bacterial infection, causing slow healing of wounds $[24,25]$. Recently, in addition to Staphylococcus aureus, drugresistance bacteria, including Klebsiella pneumonia have been found in the wounds due to the abuse of antibiotics. Our study showed that tannin extracts have obviously inhibitory effect on both Klebsiella pneumonia and Staphylococcus aureus. With the aid of an electron microscope, we observed that the cell walls of the bacteria were destroyed. However, we need to further investigate if the anti-bacterial effect is correlated with the coagulating protoplasm of microbes or multiple enzymes.

In addition, tannin extracts from Terminalia chebula Fructus Retz. could up-regulate immune-histochemical, transcriptional, and translational levels of VEGFA expression, increasing the amount of newly formed capillaries at the inflammatory phase as well as the percentage of wound contraction at the granulation formation and scar remolding phases. In addition to promoting wound healing, when compared with erythromycin ointment or Vaseline, tannin extracts have a stronger angiogenic effect. We therefore believe that tannin extracts promote wound healing, probably through their associated powerful angiogenic property. Our results indicate that tannin extracts did not affect VEGFA expression at the later stages of healing process, thereby resulting in the acceleration of wound maturity. The reason may be related to neovascularity, an indicator of immature granulation tissue, diminishing gradually with the maturing of wound $[15,20,26]$.

Recent studies showed that an infected wound usually had poor blood circulation $[27,28]$. Therefore, with effective blood concentration, an antibiotic could not reach the site of wound. In clinical practice, application of botanical drugs containing condensed tannin can obtain satisfied results. In addition to its direct anti- 
bacterial effect, it can also decrease the permeability of capillaries in the wound and alleviate tissue edema and exudation, resulting in rapid scab formation. As a result, it can effectively prevent the invasion of foreign microbes, avoiding enlargement and development of the infected wound. We need to further investigate if tannin extracts have a direct effect on an infected wound.

Although we preliminarily explored the mechanism of tannin extracts on the antibacterial effect promoting wound healing, the chemical properties, structure, physiological reaction, and pathological effects of tannin components have been unclear. Tannin may play a synergistic action with other chemical compositions. The action may interfere with other factors, thereby decreasing the effects of the botanical drug. We realize further study is necessary to reveal its mechanisms.

\section{Conclusions}

Tannin extracts from immature fruits of Terminalia chebula Fructus Retz. can promote cutaneous wound healing in rats, which probably results from a powerful angiogenic and antibacterial activity.

\section{Additional material}

\section{Additional file 1: Table S1: The percent wound contraction at}

different time point. The percent wound contraction was calculated on days $1,3,7,10,14$ and 21

Additional file 2: Table S2: Wound healing parameters of histological examination at different time point. Wound healing parameters of histological examination was calculated on days 1, 3, 7, 10 and 14

Additional file 3: Table S3: The expression of VEGFA at different time point. The expression of VEGFA was observed on days 1, 3, 7, 10 and 14

\section{Acknowledgements}

This work was supported by Dalian municipal science and technology fund (No 2008E11SF162) and fund for key laboratory from department of education of Liaoning Province(LS2010094).

\section{Author details}

${ }^{1}$ College of Life Sciences, Liaoning Normal University, Dalian 116029, PR China. ${ }^{2}$ College of Pharmacy, Dalian Medical University, Dalian 116044, PR China.

\section{Authors' contributions}

$\mathrm{KL}$ carried out the study and wrote the manuscript; HY supervised the work and the manuscript writing. BY and SSH prepared the plant extract. SYW and $\mathrm{ZZ}$ supervised the active experiment. YPD and HLZ contributed to the manuscript corrections and editing. All authors read and approved the final manuscript.

\section{Competing interests}

The authors declare that they have no competing interests.

Received: 1 June 2011 Accepted: 7 October 2011

Published: 7 October 2011

\section{References}

1. Sen CK, Khanna S, Gordillo G, Bagchi D, Bagchi M, Roy S: Oxygen, oxidants, and antioxidants in wound healing: an emerging paradigm. Ann N Y Acad Sci 2002, 957:239-249.

2. Fernandez O, Capdevila JZ, Dalla G, Melchor G: Efficacy of Rhizophora mangle aqueous bark extract in the healing of open surgical wounds. Fitoterapia 2002, 73:564-568.

3. Saleem A, Ahotupa M, Pihlaja K: Total phenolics concentration and antioxidant potential of extracts of medicinal plants of Pakistan. $Z$ Naturforsch C 2001, 56(11-12):973-978.

4. Kusirisin W, Srichairatanakool S, Lerttrakarnnon P, Lailerd N, Suttajit M, Jaikang C, Chaiyasut C: Antioxidative activity, polyphenolic content and anti-glycation effect of some Thai medicinal plants traditionally used in diabetic patients. Med Chem 2009, 5(2):139-147.

5. Nariya M, Shukla V, Jain S, Ravishankar B: Comparison of enteroprotective efficacy of triphala formulations (Indian Herbal Drug) on methotrexateinduced small intestinal damage in rats. Phytother Res 2009, 23(8):1092-1098

6. Cai $\mathrm{XH}, \mathrm{Xie} \mathrm{B}, \mathrm{Du} \mathrm{HJ}$ : Advances in research on chemical constituents and pharmacological action of Terminaliachebulda Retz. Prog Pharm Sci 2008, 32(5):212-215.

7. Chulasiri M, Wanaswas $P$, Sriaum D, Nakamat $S$, Wongkrajang $Y$, Kongsaktrakoon B, Phornchirasilp S, Songchitsomboon S, Leelarungrayub D: Utilizing hydroglycolic extract from myrobalan fruits to counteract reactive oxygen species. Int J Cosmetic Sci 2011, 33(4):371-376.

8. Terpenning MS, Bradley SF, Wan JY, Chenoweth CE, Jorgensen KA, Kauffman CA: Colonization and infection with antibiotic-resistant bacteria in a long-term care facility. J Am Geriatr Soc 1994, 42:1062-1069.

9. Frank DN, Wysocki A, Specht-Glick DD, Rooney A, Feldman RA, St Amand Al, Pace NR, Trent JD: Microbial diversity in chronic open wounds. Wound Repair Regen 2009, 17:163-172.

10. Li Feng, Chai JK: Bacterial Resistance of ESBLs Producing Escherichia coli and Klebsiella pneumoniae Isolated from Burn Wounds:A Control Study. Chin J Nosocomiol 2010, 20(19):3042-3044.

11. Mitscher LA, Park YH, Clark D: Antimicrobial agents from higher plants. Antimicrobial isoflavanoids and related substancesfrom Glycyrrhiza glabra L. var. typica. J Nat Prod 1980, 43:259-269.

12. Kolodziej H, Kayser O, Latte KP, Kiderlen AF: Enhancement of antimicrobial activity of tannins and relatedcompounds by immune modulatory effects. In Plant Polyphenols, Chemistry, Biology, Pharmacology, Ecology, 2. Edited by: Gross,GG,Hemingway, RW, Yoshida, T. Kluwer AcademicPublishers/Plenum Press; 1999:575-594.

13. Tsutomu H, Miwako K, Kazutoshi I, Tomo-omi O, Sumiko S, Tomofusa T, Takashi Y: Effects of tannins and related polyphenols on methicillinresistant Staphylococcus aureus. Phytochemistry 2005, 66:2047-2055.

14. Martin P: Wound healing-aiming for perfect skin regeneration. Science 1997, 276:75-81

15. Singer AJ, Clark RA: Cutaneous wound healing. New Engl J Med 1999, 341:738-746.

16. Kakeji Y, Maehara Y, Tomoda M, kabashima A, Ohmori M, Oda S, Ohno S, Sugimachi K: Long-term survival of patients with stage IV gastric carcinoma. Cancer 1998, 82:2307.

17. Kamat BR, Brown LF, Manseau EJ, Senger DR, Dvorak HF: Expression of vascular permeability factor/vascular endothelial growth factor by human granulosa and theca lutein cells role in corpus luteum development. Am J Pathol 1995, 146(1):157-165.

18. Chinese Pharmacopoeia Commission: Pharmacopoeia of the people's republic of china 2010; appendixl 66

19. Hebda PA, Whaley D, Kim HG, Wells A: Absence of inhibition of cutaneous wound healing in mice by oral doxycycline. Wound Repair Regen 2003 11:373-379.

20. Simonetti O, Cirioni O, Goteri G, Ghiselli R, Kamysz W, Kamysz E, Silvestri C, Orlando F, Barucca C, Scalise A, Saba V, Scalise G, Giacometti A, Offidani A: Temporin $A$ is effective in MRSA-infected wounds through bactericidal activity and acceleration of wound repair in a murine model. Peptides 2008, 29:520-528.

21. Okoli CO, Akah PA, Okoli AS: Potentials of leaves of Aspilia africana (Compositae) in wound care: an experimental evaluation. BMC Complem Altern M 2007, 7:24. 
22. Spencer CM, Cai MY, Martin R, Gaffney SH, Goulding PN, Mangolato D, Lilley TH, Haslam E: Polyphenol complexation - somethoughts and observations. Phytochemistry 1988, 27:2397-2409.

23. Haslam E: Natural polyphenols (vegetable tannins) as drugs: possible modes of action. J Nat Prod 1996, 59(2):205-215.

24. Atiyeh BS, Costagliola M, Hayekand SN, Dibo SA: Effect of silver on burn wound infection control and healing: Review of the literature. Burns 2007, 33(2):139-148.

25. Rojas IG, Padgett DA, Sheridan JF, Marucha PT: Stress-Induced Susceptibility to Bacterial Infection During Cutaneous Wound Healing. Brain Behav Immun 2002, 16(1):74-84.

26. Nayak BS, Lexley M, Pinto Pereira: Catharanthus roseus flower extract has wound-healing activity in Sprague Dawley rats. BMC Complem Altern M 2006, 6:41.

27. AlmrothE Wright: Memorandum on the treatment of infected wounds by physiological methods: ( Drainage of infected tissues by hypertonic salt solution, and utilisation of the antibacterial powers of the blood fluids and white blood corpuscles.). The Lancet 1916, 187(4842):1203-1207.

28. Nayak BS, Steve Sandiford, Anderson Maxwell: Evaluation of the Woundhealing Activity of Ethanolic Extract of Morinda citrifolia L. Leaf. EvidBased Compl Alt 2009, 6(3):351-356.

\section{Pre-publication history}

The pre-publication history for this paper can be accessed here: http://www.biomedcentral.com/1472-6882/11/86/prepub

doi:10.1186/1472-6882-11-86

Cite this article as: Li et al: Tannin extracts from immature fruits of Terminalia chebula Fructus Retz. promote cutaneous wound healing in rats. BMC Complementary and Alternative Medicine 2011 11:86.

\section{Submit your next manuscript to BioMed Central} and take full advantage of:

- Convenient online submission

- Thorough peer review

- No space constraints or color figure charges

- Immediate publication on acceptance

- Inclusion in PubMed, CAS, Scopus and Google Scholar

- Research which is freely available for redistribution

Submit your manuscript at www.biomedcentral.com/submit 